\title{
Exposição ocupacional por uso de mercúrio em odontologia: uma revisão bibliográfica
}

\author{
Occupational risk due to use of mercury in dentistry: \\ a bibliographic review
}

Jamyle Calencio Grigoletto $^{1}$
Aline da Silva Oliveira ${ }^{1}$
Susana Inés Segura Muñoz ${ }^{1}$
Leny Borghesan Albertini Alberguini $^{2}$
Angela Maria Magosso Takayanagui ${ }^{1}$

\footnotetext{
${ }^{1}$ Escola de Enfermagem de Ribeirão Preto,

Universidade de São Paulo. Av. Bandeirantes 3900 Monte Alegre. 14048-900 Ribeirão Preto SP. jamylecalencio@hotmail.com ${ }^{2}$ Laboratório de Resíduos Químicos, USP de São Carlos.
}

Abstract The aim of this study is to present data concerning hazardous waste management in the health area, with emphasis to the utilization of mercury in dentistry. The study was based on a bibliographic review regarding the use of mercury in dental fillings and its potential toxicological risks for patients and due to occupational exposure. The studies also take into consideration national and international recommendations on the use of mercury and its occupational exposure limits. The review of the literature reveals the potential toxic effects of mercury both on the environment and on human health. Given that the use of dental amalgam is still very frequent in dentistry, there is a need for safety regulations in order to minimize the risks posed by dental amalgam in dentistry proceedings based on technical guidelines for its use, discard and final disposal. Key words Amalgam, Mercury, Dentistry, Public health
Resumo Este trabalho visa apresentar dados referentes ao gerenciamento de resíduos perigosos na área da saúde, com ênfase no uso de mercúrio em odontologia. Foi elaborado com base numa revisão bibliográfica sobre o uso do mercúrio em amálgama dentário e seus potenciais riscos toxicológicos ligados à exposição, tanto de profissionais quanto de pacientes. Os estudos levantados baseiam-se também em recomendações de alguns organismos internacionais e nacionais em relação ao uso do mercúrio e seus limites de exposição ocupacional. Os dados da literatura revelam o potencial tóxico do mercúrio, tanto para o ambiente quanto para a saúde humana. Tendo em vista que o amálgama ainda é muito utilizado na odontologia, considera-se necessário uma tomada de decisão político-administrativa que vise minimizar os riscos relacionados ao uso de amálgama em procedimentos odontológicos, voltados para a segurança ocupacional, dos indivíduos e do ambiente, baseada em diretrizes e orientações técnicas sobre seu uso, descarte e disposição final.

Palavras-chave Amálgama, Mercúrio, Odontologia, Saúde pública 
As formas nas quais pode ser encontrado, além da elementar, são: mercúrio metálico $\left(\mathrm{Hg}^{0}\right)$, mercúrio I e mercúrio II, onde os átomos perdem um ou dois elétrons, respectivamente, formando mercúrio mercuroso $\left(\mathrm{Hg}_{2}{ }^{++}\right)$e o mercúrio mercúrico $\left(\mathrm{Hg}^{++}\right)^{3}$. Os sais mais importantes são: cloreto de mercúrio $\left(\mathrm{HgCl}_{2}\right)$, um sublimado corrosivo muito tóxico; cloreto mercuroso $\left(\mathrm{Hg}_{2} \mathrm{Cl}_{2}\right)$; fulminato de mercúrio $\left(\mathrm{Hg}(\mathrm{ONC})_{2}\right)$, detonador usado em explosivos; e sulfeto de mercúrio $(\mathrm{HgS})$, de cor vermelha, usado como pigmento em tintas ${ }^{1}$.

A produção mundial de mercúrio é estimada em 10.000 toneladas por ano para uso nas mais diversas áreas, como indústrias, mineração e odontologia, sendo o Canadá, a Rússia e a Espanha os principais produtores. A emissão natural de mercúrio é devida à gaseificação da crosta terrestre, emissões vulcânicas e à evaporação natural de corpos d'água. A mineração de ouro e prata, a extração de mercúrio, a queima de combustíveis fósseis e a fabricação de cimento são exemplos de fontes antropogênicas de mercúrio ${ }^{4}$.

Os problemas associados à contaminação por metais pesados têm recebido um destaque especial em vários países, independente do seu grau de desenvolvimento. O controle do mercúrio surge como uma preocupação atual devido à sua alta toxicidade e persistência na atmosfera, estando incluído no rol das Substâncias Tóxicas Persistentes, sob monitoramento pelo GEF - Global Environmental Facility (Facilidade do Ambiente Global), organização financeira independente, estabelecida em 1991, que promove a cooperação em projetos e programas internacionais voltados para a proteção do ambiente global. $\mathrm{O}$ GEF apóia e estimula a realização de projetos de sustentação relacionados à biodiversidade, à mudança de clima, às águas internacionais, à degradação da terra, à camada de ozônio e aos poluentes orgânicos persistentes, estando incluídos projetos envolvendo mercúrio 5 .

O mercúrio é utilizado em processos industriais, na fabricação de aparelhos como termômetros, esfigmomanômetros, na produção de gás cloro e de soda cáustica, em amálgamas dentários e em pilhas, sendo também encontrado na forma de compostos orgânicos em fungicidas, bactericidas e inseticidas ${ }^{6}$. É também usado em vários tipos de lâmpadas elétricas, incluindo as fluorescentes e as de descarga de alta densidade; em interruptores, retificadores e termostatos elétricos; em bombas de difusão a vapor de mercúrio; em manômetros; e em outros tipos de instrumentos de pressão, medição e calibração ${ }^{7}$.
O mercúrio, portanto, possui uma ampla utilização, tanto na indústria quanto na odontologia; porém, pode acarretar sérios danos se utilizado de maneira indiscriminada ou inadequada ${ }^{8}$.

O mercúrio causa graves problemas de corrosão, devido à alta mobilidade, tendência à dispersão e facilidade com que forma amálgamas ou ligas com a maioria dos metais, exceto o ferro. O mercúrio aquecido emite fumos altamente tóxicos ${ }^{3}$.

Para a saúde humana, o mercúrio representa um grande risco, pela toxicidade e danos no nível celular e orgânico do organismo humano. Goldman e Shannon ${ }^{9}$ afirmam que o mercúrio, em todas as suas formas, é tóxico para fetos e crianças, devendo ser reduzida a exposição de mulheres grávidas e crianças, bem como da população em geral.

Um exemplo claro e trágico na história, que despertou grande interesse e preocupação, principalmente na academia, foi o envenenamento que ocorreu em Minamata, no Japão, em 1960, onde uma indústria de aldeídos, que utilizava o metilmercúrio como agente catalisador, despejava seus resíduos na Baía de Minamata, contaminando a água e os peixes, que eram consumidos pela população local. Isso causou grandes agravos à saúde da população, desencadeando a morte de 65 pessoas por intoxicação e o nascimento de crianças com grandes distúrbios genéticos, principalmente neurológicos ${ }^{10,11}$.

Sabendo-se da intensa utilização de amálgama dentário e da problemática relacionada ao gerenciamento de resíduos perigosos na área da saúde, foi realizado um levantamento na literatura científica, com o objetivo de conhecer dados referentes ao tipo de gerenciamento que vem sendo dado a esses resíduos, com ênfase no uso de mercúrio em odontologia. O trabalho foi elaborado com base numa revisão bibliográfica sobre o uso do mercúrio em amálgama dentário e seus potenciais riscos toxicológicos ligados à exposição, tanto de profissionais quanto de pacientes. Os estudos levantados baseiam-se também em recomendações de alguns organismos internacionais e nacionais em relação ao uso do mercúrio e seus limites de exposição ocupacional.

Os artigos foram levantados junto à base de dados BBO (Bibliografia Brasileira de Odontologia), além de outras bases eletrônicas e acervos bibliográficos da Biblioteca Central da Universidade de São Paulo de Ribeirão Preto, no período de maio a julho de 2005 , utilizando-se como descritores amálgama odontológico e mercúrio. 
Os resultados apontam que há um grande número de estudos experimentais na literatura sobre efeitos neuro-teratogênicos pela exposição do mercúrio, onde ambos, humanos e animais, expostos a baixas doses de mercúrio no útero e logo depois do nascimento, revelam um déficit considerável de inteligência, coordenação motora e outros problemas neurológicos ${ }^{12-18}$.

De acordo com os trabalhos levantados, os efeitos tóxicos do mercúrio são expressos de modos diferentes, de acordo com a forma química do mercúrio, a dose e a rota de exposição ${ }^{19}$.

No entanto, há duas formas principais de efeitos tóxicos do mercúrio, a saber: efeitos nefrotóxicos e efeitos neurotóxicos ${ }^{2}$. O vapor de mercúrio, quando inalado, entra na corrente sanguínea e se transforma por oxidação em íon $\mathrm{Hg}^{-}$. Devido ao fato dessa reação não ser instantânea, o metal permanece em sua forma elementar por alguns minutos, no sistema circulatório, e se deposita nas células nervosas concluindo sua oxidação final, podendo ainda transpor a barreira placentária. $\mathrm{O}$ íon $\mathrm{Hg}^{-}$se deposita nos tecidos do córtex cerebral, cerebelo e também no núcleo cerebral ${ }^{20}$.

Em altos teores, o mercúrio pode prejudicar o cérebro, o fígado, o desenvolvimento de fetos e causar vários distúrbios neuropsiquiátricos. $\mathrm{O}$ sistema nervoso humano é também muito sensível a todas as formas de mercúrio que, ao ser inalado sob a forma de vapor ou ingerido, atinge diretamente o cérebro, podendo causar irritabilidade, timidez, tremores, distorções da visão e da audição e problemas de memória. Pode haver também problemas nos pulmões, náuseas, vômitos, diarréia, elevação da pressão arterial e irritação nos olhos, pneumonia, dores no peito, dispnéia e tosse, gengivite e salivação ${ }^{3}$.

O metilmercúrio também se acumula avidamente no cabelo. A concentração no escalpo humano formado é diretamente proporcional à concentração simultânea no sangue. Assim que incorporado dentro da fibra do cabelo, sua concentração permanece estável, de modo que o cabelo serve como registro histórico de níveis sanguíneos anteriores ${ }^{2}$.

Como observado por Skerfving ${ }^{21}$, a maior parte do metilmercúrio no sangue encontra-se nos glóbulos vermelhos, o que os torna um meio indicador desejável. Já o plasma é mais apropriado para monitorar o mercúrio inorgânico, pois este se distribui sempre entre o plasma e os eritrócitos.

\section{Normatização da exposição ao mercúrio}

Segundo Guimarães ${ }^{2}$, no Brasil, os valores admissíveis para presença do mercúrio no ambiente e nos organismos vivos são estabelecidos por normas com limites de tolerância biológica. A legislação brasileira, seguindo as normas regulamentadoras (NRs) do Ministério do Trabalho e da Organização Mundial de Saúde, e também de acordo com a NBR 10004 de 2004, da Associação Brasileira de Normas Técnicas ${ }^{22}$, estabelece como limite de tolerância biológica para o ser humano, a taxa de $33 \mathrm{ug} \mathrm{Hg} / \mathrm{g}$ de creatinina urinária e 0,04 $\mathrm{mg} \mathrm{Hg} / \mathrm{m}^{3}$ no ambiente de trabalho. Assim, ocupa lugar de destaque entre as substâncias mais perigosas relacionadas nessas normas.

De acordo com a NBR 10004/04, os resíduos gerados em diferentes fontes produtoras podem ser classificados de acordo com o grau de risco ou periculosidade para a saúde e ambiente, ou seja: resíduos Classe I - perigosos e Classe II não perigosos, podendo, os resíduos Classe II, ser não inertes (Classe II A) ou inertes (Classe II B). Os resíduos Classe I são considerados perigosos por apresentarem uma das cinco características: toxicidade, reatividade, inflamabilidade, corrosividade e patogenicidade. O mercúrio inclui-se como Classe I pelo risco, principalmente, ligado à toxicidade e patogenicidade humana, além da contaminação ambiental ${ }^{22}$.

Por sua vez, a Norma Regulamentadora NR15, estabelecida pela Portaria $n^{\circ} 3214$, de 08 de junho de 1978, do Ministério do Trabalho do país, que trata das atividades e operações em locais insalubres, também considera o mercúrio como um dos principais agentes nocivos que afetam a saúde do trabalhador, considerando-o como de insalubridade de grau máximo. O limite de tolerância para os fins desta norma é a concentração ou intensidade máxima ou mínima, relacionada com a natureza e o tempo de exposição ao agente, que não causar danos à saúde do trabalhador, durante sua vida laboral. E a NR-15 preconiza como limite de tolerância para uma jornada de trabalho de até 48 horas semanais o valor de $0,040 \mathrm{mg} \mathrm{Hg} / \mathrm{m}^{3}$, para os trabalhadores que estão expostos ao mercúrio durante a sua atividade profissional ${ }^{23}$.

Na Tabela 1, podem-se observar os valores de referência propostos pela OSHA - Occupational Safety \& Health Administration (Agência de Saúde e Segurança Ocupacional), uma agência federal norte-americana que edita e aplica regulamentações sobre segurança e saúde ocupacional para empresas e indústrias nos Estados Unidos; e, tam- 
bém por outros órgãos norte-americanos, como NIOSH - The National Institute for Occupational Safety and Heath (Instituto Nacional de Saúde e Segurança Ocupacional), agência federal que coordena ações profissionais nas áreas de saúde e segurança ocupacional, realizando pesquisas em diversos temas relacionados à saúde e segurança ocupacional com a certificação de vários equipamentos de segurança para uso no ambiente de trabalho; ACGIH - American Conference of Governmental Industrial Hygienists (Conferência Americana de Higienistas Industriais Governamentais), sítio mantido por uma organização internacionalmente respeitada, constituída por comunidade de profissionais que tratam da higiene e saúde ambiental e ocupacional e da segurança industrial, desenvolvendo e publicando pesquisas e limites recomendados de exposição ocupacional denominados TLVs -Threshold Limit Values (Valores Limites de Exposição), para centenas de substâncias químicas ${ }^{24}$.

TLV é a concentração no ar de substâncias selecionadas pela ACGIH, que representam condições, nas quais se acredita que praticamente todos os trabalhadores podem ser expostos continuamente sem efeitos adversos. TLVs são guias de aconselhamento, não sendo padrões legais, mas padrões baseados em evidências de experiência industrial, de estudos com animais, ou com humanos. Há diferentes tipos de TLVs: TLV-TWA - Time Weighted Average (Média Ponderada pelo
Tempo), TLV-STEL - Short Term Exposure Limit (Limite de Curta Exposição) e TLV-C - Ceiling (Teto ou Limite Máximo).

- O TWA, Time Weighted Average, (Média Ponderada pelo Tempo) é considerado o tempo médio, relativo a um período de trabalho (por exemplo, 8 horas/dia) da exposição de uma pessoa a um agente químico. A média é determinada por amostragem do contaminante ao longo do período. É representado por TLV-TWA;

- O STEL ou TLV-STEL, Short Term Exposure Limit (Limite de Curta Exposição), consiste na concentração máxima à qual indivíduos podem ser expostos por um curto período (15 minutos), por apenas quatro vezes ao dia ao longo da jornada, e com intervalos de pelo menos 1 hora entre as exposições. O limite diário (TLVTWA) também não pode ser excedido;

- O TLV-C, Threshold Limit Value-Ceiling (Teto ou Limite Máximo) é uma descrição geralmente associada a um limite de exposição. Refere-se à concentração que não deve ser ultrapassada, nem por um instante ${ }^{24}$.

Analisando os valores limites estabelecidos pela OSHA, NIOSH e ACGIH, verifica-se que esses são semelhantes para todos os compostos de mercúrio (alquil, aril e compostos inorgânicos de mercúrio). De acordo com a Tabela 1, observa-se também que, para o composto alquil mercúrio (metilmercúrio), os limites de exposição para 8 horas de trabalho são até dez vezes menores com-

Tabela 1. Limites de exposição aos vapores de Hg segundo OSHA, NIOSH e ACGIH, no ano de 2003.

\begin{tabular}{|c|c|c|c|}
\hline & \multicolumn{3}{|c|}{ Limites de exposição } \\
\hline & $\begin{array}{c}\text { Compostos } \\
\text { Alquil, Hg }\end{array}$ & $\begin{array}{c}\text { Compostos } \\
\text { Aril, } \mathrm{Hg}\end{array}$ & $\begin{array}{c}\text { Compostos } \\
\text { inorgânicos, } \mathrm{Hg}\end{array}$ \\
\hline \multicolumn{4}{|l|}{ OSHA } \\
\hline 8-horas TWA & $0,01 \mathrm{mg} / \mathrm{m}^{3}$ & - & \\
\hline Teto & $0,04 \mathrm{mg} / \mathrm{m}^{3}$ & $0,1 \mathrm{mg} / \mathrm{m}^{3}$ & $0,1 \mathrm{mg} / \mathrm{m}^{3}$ \\
\hline \multicolumn{4}{|l|}{ NIOSH } \\
\hline 8-horas TWA & $0,01 \mathrm{mg} / \mathrm{m}^{3}$, pele & $0,05 \mathrm{mg} / \mathrm{m}^{3}$, pele & $0,05 \mathrm{mg} / \mathrm{m}^{3}$, pele \\
\hline ST/Teto & $0,03 \mathrm{mg} / \mathrm{m}^{3},(\mathrm{ST})$ pele & $0,1 \mathrm{mg} / \mathrm{m}^{3}$, (Teto) pele & $0,1 \mathrm{mg} / \mathrm{m}^{3}$, (Teto) pele \\
\hline IDLH & $2 \mathrm{mg} / \mathrm{m}^{3}$ & $10 \mathrm{mg} / \mathrm{m}^{3}$ & $10 \mathrm{mg} / \mathrm{m}^{3}$ \\
\hline \multicolumn{4}{|l|}{ ACGIH } \\
\hline 8-horas TWA & $0,01 \mathrm{mg} / \mathrm{m}^{3}$, pele & $0,1 \mathrm{mg} / \mathrm{m}^{3}$, pele & $0,025 \mathrm{mg} / \mathrm{m}^{3}$, Teto \\
\hline Limite de exposição curta & $0,03 \mathrm{mg} / \mathrm{m}^{3}$, pele & - & - \\
\hline
\end{tabular}


parando com os outros compostos (aril e mercúrio inorgânico). No Brasil, não existe na legislação a divisão do mercúrio em compostos alquil e aril; os limites de exposição são estabelecidos para o composto mercúrio, de um modo geral.

\section{Exposição ocupacional ao mercúrio}

O mercúrio metálico $\left(\mathrm{Hg}^{0}\right)$ é a forma que apresenta maior risco ocupacional, devido à formação de vapores inodoros e incolores, com facilidade de penetração por vias respiratórias ${ }^{25}$. Segundo Langhan ${ }^{26}$, trabalhadores de mais de sessenta tipos de indústrias apresentaram risco ocupacional com o mercúrio, incluindo-se trabalhadores de fábricas de cloro, soda cáustica, inseticidas, fungicidas, luzes néon, tintas e papéis. A exposição ao mercúrio pode ocorrer ao se respirar ar contaminado, por ingestão de água e comida contaminada e durante tratamentos dentários.

Exposição ocupacional em serviços odontológicos

O amálgama dental tem sido usado por mais de 150 anos; Gainsford e Dunne ${ }^{27}$ relataram que o primeiro amálgama de prata odontológico provavelmente foi introduzido na Inglaterra por Joseph Bell, em 1819. Sabe-se também que os precursores da utilização da mistura do amálgama em temperatura ambiente foi o dentista francês Onessiphore Taveau, em 1876, que defendia o uso da "pasta prata" para as restaurações permanentes, e o químico inglês Charles Bell, que utilizava moedas de prata trituradas com o mercúrio ${ }^{6}$.

Wasylko et al. ${ }^{28}$ relatam que, de acordo com Mandel, a preocupação em torno da exposição ocupacional teve importância devido à inadequação dos procedimentos de higiene relacionados ao mercúrio, da década de 70 até o início dos anos 80, na maioria dos atendimentos odontológicos.

Segundo Saquy ${ }^{25}$, em 1840, a Sociedade Americana de Cirurgião-Dentista reconheceu o amálgama e todas as substâncias com mercúrio como nocivas aos dentes e todas as partes da boca. Sto$\mathrm{ck}^{29}$ identificou o amálgama como fonte de vapor de mercúrio e alertou que este deveria ser abolido da odontologia.

Wannag e Skjaerasen ${ }^{30}$, em estudo realizado com mulheres grávidas dentistas e não dentistas, verificaram que as dentistas apresentaram acúmulo de mercúrio na placenta e membranas fetais, e que estes órgãos serviriam de proteção ao feto contra exposição ao metal. No entanto, autores como Vimy, Takahash e Lorscheider ${ }^{31}$ constataram que restaurações de amálgama feitas em mulheres grávidas promoviam contaminação dos fetos em poucas horas, pois, segundo os autores, a placenta não impede a passagem do mercúrio. Assim como outros autores, que também demonstraram que há uma intoxicação fetal pela passagem do metal através da placenta ${ }^{32}$.

Segundo Campos e Steagall ${ }^{33}$, o mercúrio tem influência nas propriedades do amálgama dentário, e, por isso, é um dos elementos essenciais para a sua preparação. Porém, alguns autores destacam o perigo que representa para a saúde dos profissionais odontólogos e de seus auxiliares, uma vez que a contaminação pode ocorrer por contato direto do metal com a pele ou através da inalação de seus vapores. Gronka et al. ${ }^{34}$ mostraram que a operação de maior risco de contaminação em relação ao mercúrio estava na fase de preparação do amálgama.

O amálgama odontológico é obtido através da reação do mercúrio com um pó metálico (liga de prata $[\mathrm{Ag}]$, cobre $[\mathrm{Cu}]$ e estanho $[\mathrm{Sn}]$, basicamente) e contém, em média, $53 \%$ de mercúrio. $\mathrm{O}$ problema é que cerca de $55 \%$ do amálgama preparado por dentistas são perdidos durante a preparação, e este material é freqüentemente descartado como lixo comum, conforme constataram Ferreira e Appel ${ }^{35}$. Como via de regra, o conteúdo ministrado em disciplinas de materiais dentários determina que o mercúrio não deve permanecer no amálgama em porcentagem superior a $50 \%{ }^{36}$. Atualmente, como método de preparo das restaurações de amálgama, é recomendada a técnica de EAMES, que compreende a proporção limalha/Hg de $1: 1^{37}$.

$\mathrm{Na}$ literatura científica, há uma vasta produção de estudos que revelam que o mercúrio derivado do amálgama dentário se espalha pelo corpo. Vários estudos de necrópsias mostram a correlação entre a concentração de mercúrio em vários tecidos e órgãos de cadáveres humanos e o número de restaurações ou superfícies de amálgamas presentes ${ }^{38-42}$. Alguns autores relatam que as concentrações de mercúrio encontradas na urina, sangue e fezes diminuem após a remoção das restaurações de amálgama ${ }^{43,44,21}$.

Naleway et al. ${ }^{45}$, em um estudo realizado entre 1975 e 1983, analisando os níveis de mercúrio urinário em 4.272 dentistas, encontraram que, em média, os dentistas não apresentavam concentrações urinárias de mercúrio acima do limite, concluindo então, que não havia problema de exposição ocupacional deles com relação ao amál- 
gama. Entretanto, as concentrações urinárias foram estatisticamente significantes $(\mathrm{p}<0,001)$ quando correlacionadas com o número de restaurações de amálgama que cada dentista colocava por semana. A população geral dos dentistas do estudo apresentava um intervalo de 0-5 ug de $\mathrm{Hg} / \mathrm{L}$ de urina, enquanto $10,9 \%$ deles apresentavam concentrações maiores que 30 ug de $\mathrm{Hg} / \mathrm{L}$ de urina, incluindo 1,3\% com níveis acima de 100 ug de $\mathrm{Hg} / \mathrm{L}$ de urina.

De acordo com a Organização Mundial da Saúde, em 1991, num encontro entre toxicologistas e especialistas em saúde ambiental, uma pessoa no mundo industrial com restaurações de amálgama e sem exposição ocupacional ao mercúrio poderia absorver entre 3-17 ug por dia, com uma média de $10 \mathrm{ug}$ provenientes de restaurações dentais; 2,3 ug provenientes da dieta e 0,3 ug, de outras fontes ambientais ${ }^{46}$.

Considerando que os dentistas passam em média 40 horas/semana em seus consultórios, esses profissionais devem se preocupar com os vapores de mercúrio liberados dos resíduos de amálgama, pois podem estar expostos a grandes concentrações de mercúrio, que, com o passar do tempo, poderia provocar fadiga, esclerose múltipla, arteriosclerose, doença de Alzheimer, nervosismo, irritabilidade, dores de cabeça e instabilidade emocional ${ }^{25}$.

Assim, os amálgamas dentários têm sido considerados como principal fonte de exposição ocupacional ao vapor de mercúrio ${ }^{47}$.

\section{Manuseio e gerenciamento do amálgama}

Os profissionais da equipe de saúde bucal estão expostos diariamente ao mercúrio e a seus riscos de contaminação, que pode ocorrer por meio de diferentes fatores, como: pela manipulação do amálgama, gotas do metal derramadas acidentalmente, remoção do excesso do mercúrio do amálgama, por amalgamadores com vazamento, por falhas do sistema de sucção, quando da remoção de restaurações antigas ${ }^{25}$, ou pela presença de restos de amálgama armazenados inadequadamente nos consultórios ${ }^{48,6}$. A presença de fontes de calor, como estufas e autoclaves, no mesmo ambiente onde o amálgama é manipulado, aumenta as possibilidades de intoxicação mercurial ${ }^{6}$.

Saquy $^{25}$ fez um estudo comparativo sobre a eficácia de diversas substâncias na retenção da emissão de vapores de mercúrio originários de resíduos de amálgama e concluiu que a solução fixadora de radiografias era a mais eficaz, sendo capaz de reter os vapores por dezessete dias; em segundo lugar, apareceu a água, que reteve o metal durante catorze dias.

Fortes e Samuel ${ }^{49}$, em um estudo que teve também como objetivo avaliar a eficácia de meios para o armazenamento de resíduos de amálgama, compararam diferentes meios como: glicerina, água destilada, solução fixadora de radiografias e meio seco, visando à diminuição da liberação de vapores de mercúrio para o ar do ambiente de trabalho. Os autores encontraram que a glicerina foi o meio mais adequado para a armazenagem de resíduos de amálgama de prata.

A recomendação da ADA - Associação Dental Americana é colocar os resíduos de amálgama em recipientes inquebráveis, hermeticamente fechados e imersos em solução fixadora de radiografias $^{50}$.

\section{Exposição de pacientes por $\mathrm{Hg}$}

Para Claro et al. ${ }^{6}$, o ambiente contaminado dos consultórios constitui um risco não apenas para os profissionais, como também para os pacientes.

Um tópico de interesse considerável é o papel desempenhado pelas restaurações de amálgama, que são consideradas fontes potenciais de contaminação pelo mercúrio, através dos vapores de mercúrio liberados por elas no ar e na cavidade oral, ou por meio da absorção pela mucosa bucal $^{51,52,31}$. A taxa de liberação é profundamente incrementada pelo ato da mastigação. A natureza do alimento também afeta esta taxa; além disso, o mercúrio é liberado como resultado do processo de corrosão e atrição do amálgama ${ }^{25}$.

O mercúrio contido nas restaurações de amálgama tem contribuído para a ocorrência de respostas alérgicas na forma de dermatites em indivíduos atópicos. Essas respostas desaparecem à medida que são removidas as restaurações ${ }^{48}$.

Frykholm ${ }^{53}$ concluiu que a quantidade calculada de exposição ao mercúrio proveniente das restaurações de amálgama não era suficiente para causar envenenamento por mercúrio. Em estudos mais recentes, considerou-se que a absorção de mercúrio orgânico relacionado com a ingestão de alimentos era seis vezes maior que a ingestão de mercúrio por amálgamas; um outro fator é que o mercúrio de origem alimentar é mais tóxico ${ }^{54}$.

Alguns estudos relatam que a restauração de amálgama pode liberar de 2 a 20 mg de mercúrio diariamente $^{52}$ e que a liberação de mercúrio das restaurações de amálgama pode provocar into- 
xicações e acúmulo do metal em fetos de mães que possuem tais restaurações ${ }^{31}$. No entanto, Wasylko et al. ${ }^{28}$ concluíram que as pequenas quantidades de mercúrio liberadas de restaurações de amálgama não são provavelmente nocivas ao feto. Como precaução, os cirurgiões-dentistas devem estar orientados a não remover ou inserir estas restaurações em pacientes grávidas.

Contaminação ambiental por mercúrio proveniente dos serviços odontológicos

Na literatura, pouco se encontra sobre condições relacionadas ao descarte no ambiente de resíduos de mercúrio utilizados na odontologia, o que é muito importante, visto que na troca de restaurações, ou na remoção dos excessos de restaurações de amálgama, os resíduos são captados pelos sugadores e despejados na rede de esgoto, chegando até as estações de tratamento de efluentes ou diretamente nos rios ${ }^{6}$.

A contaminação ambiental por mercúrio proveniente de amálgamas dentários é de 3 a $4 \%$ quando comparada à industrial e de combustíveis fósseis. Segundo Ferreira e Appel ${ }^{35}$, estima-se que no Brasil cerca de dezesseis toneladas de mercúrio são empregadas, anualmente, em serviços odontológicos. Considerando uma perda relatada em estudos de cerca de $55 \%$ de amálgama em consultórios odontológicos, pode-se pensar, portanto, que cerca de oito toneladas de mercúrio, oriundo dos consultórios odontológicos, são descartadas no meio ambiente, por ano. No entanto, esse descarte pode ser minimizado, se equipamentos de coleta e segregação forem acoplados às saídas de água das clínicas dentárias, para que aqueles resíduos possam ser submetidos a um tratamento. Valenzuela ${ }^{55}$, Leite, Souza e Araújo ${ }^{56}$ e Souza et al. $^{57}$ apresentaram propostas viáveis ao meio odontológico para a reciclagem de resíduos de amálgama de prata, visando um maior controle da contaminação ambiental pelo mercúrio utilizado na odontologia.

\section{Considerações finais}

Os resíduos de serviços de saúde têm gerado, no meio científico e acadêmico, uma grande polêmica a respeito dos impactos que podem causar tanto à saúde pública como à saúde ambiental.

Sabe-se que o mercúrio é um metal tóxico que a longo prazo se aloja em tecidos e órgãos humanos, podendo não estar mais presente na urina e, sim, depositado nos tecidos e órgãos, dificultando o diagnóstico de intoxicação mercurial.

Através da presente revisão da literatura científica sobre o tema, fica evidente a toxicidade e o risco que o mercúrio liberado no meio ambiente causa quando atinge a cadeia alimentar. No entanto, a possível contribuição de mercúrio através do uso odontológico do amálgama dental pode ser controlada com medidas preventivas de segurança, com relação ao mercúrio, aos resíduos dele decorrentes, bem como da manipulação e disposição final desse elemento.

Por muitos anos, tem-se afirmado que o amálgama dental não causa doença humana, exceto raras reações alérgicas, mas há algumas indicações científicas na literatura e muitas sugestões de que a exposição crônica ao mercúrio pode contribuir para sérias doenças; devido a isso, faz-se necessário o uso adequado desse material, bem como a otimização do gerenciamento de risco decorrente desse elemento ${ }^{58}$.

É recomendado, para minimizar o risco, a utilização de substâncias químicas de menor toxicidade. No caso do mercúrio utilizado em amálgamas dentários, isso nem sempre é possível, devido às dificuldades tecnológicas e econômicas envolvidas, visto que o amálgama ainda é um material muito utilizado e considerando que não existe outro material com as mesmas propriedades, como fácil manipulação, alta durabilidade e baixo custo, que seja compatível com o amálgama. Sendo assim, os profissionais da equipe de saúde bucal devem se conscientizar quanto aos riscos e cuidados a serem tomados para a utilização e manipulação do mercúrio contido no amálgama odontológico.

Ainda, o artigo 22 da Resolução SS-15, de 18 de janeiro de 1999, do Centro de Vigilância Sanitária da Secretaria de Estado da Saúde de São Paulo, dispõe sobre áreas físicas dos estabelecimentos de assistência odontológica, recomendando que esses estabelecimentos devam apresentar: iluminação que possibilite boa visibilidade, sem ofuscamentos ou sombras; ventilação que possibilite circulação e renovação de ar; revestimentos de pisos com material lavável e impermeável, que possibilite os processos de descontaminação e/ou limpeza, sem a presença de trincas, ou descontinuidades; paredes de alvenaria ou divisórias de cor clara, revestidas de material lavável e impermeável, que possibilite os processos de descontaminação e/ou limpeza, sem a presença de mofo ou descontinuidades; forros de cor clara, sem presença de infiltrações, rachaduras ou mofo; instalações hidráulicas e elétricas 
embutidas ou protegidas por calhas ou canaletas externas, para que não haja depósitos de sujidades em sua extensão ${ }^{59}$.

A ventilação é a melhor medida de segurança; se inadequada, os trabalhadores deverão usar proteção individual. O mercúrio deve, então, ser manuseado em sistemas hermeticamente fechados e dentro de normas de higiene. Em caso de derramamento, este pode infiltrar-se facilmente nas saliências ou rachaduras do solo, do piso e das bancadas de trabalho. Sua pressão de vapor permite que atinja concentrações atmosféricas altas, mesmo após contaminações aparentemente desprezíveis ${ }^{3}$.

Ao se trabalhar com o mercúrio, as superfícies devem ser lisas, pouco absorventes e permitir, em caso de derramamento, que os compostos sejam desviados em direção a um coletor ${ }^{6}$.

Apesar da legislação brasileira ter determinado normas e condutas rigorosas para o gerenciamento de resíduos sólidos perigosos, apenas a lei e a tecnologia não são suficientes para que a problemática dos resíduos, principalmente daqueles gerados em serviços de saúde, seja solucionada; há a necessidade de se investir em treinamentos teórico-práticos sobre manuseio adequado desses resíduos e em educação ambiental.

A promoção contínua de trabalhos educativos para conscientizar a população e, principalmente, os profissionais da equipe de saúde bucal sobre os danos à saúde humana e ao meio ambiente, bem como sobre as formas de seu gerenciamento adequado, ao lado de um sistema de monitoramento e controle dos geradores desses resíduos, são medidas que podem colaborar sensivelmente para minimizar a contaminação do ambiente de trabalho e de todo ecossistema, além dos riscos de exposição humana através dos resíduos despejados na rede de esgoto e emanados no ar.

Vale destacar que não há, nem na literatura levantada, nem em normas e guias técnicos e legais nacionais, uma orientação clara baseada em estudos e evidências que permitam uma destinação final desses resíduos sem causar danos ao ambiente e à saúde pública.
Essa revisão, a nosso ver, revela que, apesar dos benefícios que envolvem o uso do amálgama em procedimentos odontológicos, pelas suas propriedades, como a facilidade de manuseio, alta durabilidade e baixo custo, ainda prevalece um fator negativo, relacionado ao seu uso, quando se reporta aos impactos gerados na saúde, tanto ocupacional quanto do paciente, e também, no ambiente, pelos riscos de contaminação dos recursos naturais necessários para a promoção de uma adequada qualidade de vida.

\section{Colaboradores}

JC Grigoletto contribuiu para a elaboração do levantamento bibliográfico, leitura e discussão dos artigos levantados na revisão e participou da elaboração e revisão final do artigo com a equipe de pesquisadores. AS Oliveira contribuiu para a elaboração do levantamento bibliográfico, leitura e discussão dos artigos levantados na revisão e participou da elaboração do artigo com a equipe de pesquisadores. SIS Muñoz contribuiu com a leitura e discussão dos artigos levantados na revisão e colaborou na elaboração do artigo com a equipe de pesquisadores. LBA Alberguini contribuiu com a leitura e discussão dos artigos levantados na revisão e colaborou na elaboração do artigo com a equipe de pesquisadores. AMM Takayanagui orientou a investigação, contribuiu com a leitura e discussão dos artigos levantados na revisão e participou da elaboração e revisão final do artigo com a equipe de pesquisadores. 
Referências

1. Tomes CPS System [CD-ROM]. Mercury. Englewood: Micromedex; 2000.

2. Guimarães GA. Efeitos tóxicos do mercúrio. [acessado 2005 Jul 23]. Disponível em: http://www. ambientebrasil.com.br/composer.php3? base=residuos/index.php3\&conteudo=./residuos/ artigos/toxicidade_mercurio.html

3. Azevedo FA, Nascimento ES, Chasin AM. Mercúrio. In: Azevedo FA, Chasin AAM, organizadores. $\mathrm{Me}$ tais: gerenciamento da toxicidade. São Paulo: Atheneu; 2003. p. 299-352.

4. Carmo DA. Vida e morte nos rios. [acessado 2005 Jun 21]. Disponível em: http://www.ambientebrasil. com.br/composer.php3 ?base=./agua/doce/index. html\&conteudo=./agua/vidaemorte.html

5. Global Environmental Facility. 2005. [acessado 2005 Jun 23]. Disponível em: http://www.unites.uqam.ca/ gmf/intranet/gmp/organization/gef_gmp.htm

6. Claro FA, Ito FR, Bastos FM, Ribeiro ME. Mercúrio no amálgama odontológico: riscos da exposição, toxicidade e métodos de controle-revisão da literatura. [acessado 2005 Jun 23]. Disponível em: http://www.bvsde.paho.org/bvsacd/cd49/mercurio amalg-N1-2003.pdf

7. Canadian Center for Occupational Health and Safety. 2000. [acessado 2005 Jun 23]. Disponível em: http:/ /www.ccohs.ca/resources/

8. Lima GA. A segurança e os riscos do mercúrio utilizado no amálgama dental: revisão bibliográfica [dissertação]. Ribeirão Preto (SP): Escola de Enfermagem de Ribeirão Preto/ Universidade de São Paulo; 2001.

9. Goldman LR, Shannon MW. Technical report: mercury in the environment: implications for pediatricians. American Academy of Pediatrics: Committee on Environmental Health 2001; 108(1):197-205.

10. Weiss B. Long ago and far away: retrospective on the implications of Minamata. NeuroToxicology 1996; 17(1):257-264.

11. Harada M, Nakanishi J, Konuma S, Ohno K, Kimura T, Yamaguchi H, Tsuruta K, Kizaki T, Ookawara T, Ohno H. The present mercury contents of scalp hair and clinical symptoms in inhabitants of the Minamata area. Environmental Research 1998; 77(2):160-164.

12. Eccles CU, Annau Z. Prenatal methyl mercury exposure: II. Alterations in learning and psychotropic drug sensitivity in adult offspring. Neurobehav Toxicol Teratol 1982; 4(3):377-382.

13. Berlin M, Jua J, Logdberg B, Warfvinge K. Prenatal exposure to mercury vapor: effects on brain development. Fund Appl Toxicol 1992; 19:324-326.

14. Fredriksson A, Dahlgren L, Danielsson B, Eriksson P, Dencker L, Archer T. Behavioral effects of neonatal metallic mercury exposure in rats. Toxicology 1992; 74(2-3):151-160.

15. Danielsson BR, Fredriksson A, Dahlgren L, Gardlund AT, Olsson L, Dencker L, Archer T. Behavioral effects of prenatal metallic mercury inhalation exposure in rats. Neurotoxicol Teratol 1993; 15(6):391-396.

16. Aschner M, Lorscheider FL, Cowan KS, Conklin DR, Vimy MJ, Lash LH. Metallothionein induction in fetal rat brain and neonatal primary astrocyte cultures by in utero exposure to elemental mercury vapor. Brain Research 1997; 778(1): 222-232.
17. Grandjean P, Weihe P, White RF, Debes F, Araki S, Yokoyama K, Jørgensen PJ. Cognitive deficit in 7 year old children with prenatal exposure to methyl mercury- neuroradiologic and electrophysiologic studies. Neurotoxicol Teratol 1997; 19(6):417-428.

18. Grandjean P, Weihe P, White RF, Debes F. Cognitive performance of children prenatally exposed to "safe" levels of methyl mercury. Environmental Research 1998; 77(2):165-172.

19. Agency for Toxic Substances and Disease Registry. U.S. Department of Health and Human Services, Public Health Service. Mercury. 1999. [acessado 2005 Jul 20]. Disponível em: http://www.atsdr.cdc.gov/ cabs/mercury/

20. Lowe JM. Mercury vapor exposure in the dental office. Dental Hyg 1980; 54(3):118-120.

21. Skerfving S. Exposure to mercury in the population. In: Suzuki T, Imura N, Clarkson TW, editors. Advances in Mercury Toxicology. New York: Plenum Press; 1991. p. 411-425.

22. Associação Brasileira de Normas Técnicas. NBR 2004. Resíduos Sólidos - Classificação. 2004. [acessado 2005 Jul 20]. Disponível em: http://www.abnt.org.br/imagens/NOTATECNICACONSOLIDADOFINAL.pdf

23. Lei $n^{\circ} 6.514$, de 22 de Dezembro de 1977. Altera o Capítulo V do Titulo II da Consolidação das Leis do Trabalho, relativo à segurança e medicina do trabalho e dá outras providências. Diário Oficial da União 1977; 23 dez.

24. Comissão Interna de Segurança Química. Instituto de Biociências, Letras e Ciências Exatas. UNESP, São José do Rio Preto - SP. 2005. [acessado 2005 Jun 23]. Disponível em: http://www.qca.ibilce.unesp.br

25. Saquy PC. Identificação qualitativa de vapor de mercúrio captado de resíduo de amálgama de prata em diferentes meios de armazenagem [tese de livre docência]. Ribeirão Preto (SP): Faculdade de Odontologia/ Universidade de São Paulo; 1996.

26. Langhan DC. The use of mercury in dentristy: a critical review of the recent literature. J Am Dent Assoc 1987; 155(6):867-880.

27. Dunne SM, Gainsford ID, Wilson NHF. Current materials and techniques for direct restorations in posterior teeth. Part1: Silver amalgam. Int Dent $J$ 1997; 47(3):123-136.

28. Wasylko L, Matsui D, Dykxhoorn SM, Rieder MJ, Weinberg S. A review of common dental treatments during pregnancy: implications for patients and dental personnel. J Can Dent Assoc 1998; 64(6):434-439.

29. Stock A. Die Gefahrlichkeit des quecksilberdampfes. Z Angew Chem 1926; (39):461-488.

30. Wannag A, Skjaerasen J. Mercury accumulation in placenta and fetal membranes. A study of dental workers and their babies. Environ Physiol Biochem 1975; 5(5):348-352.

31. Vimy MJ, Takahash Y, Lorscheider FL. Maternal fetal distribution of mercury $(203 \mathrm{Hg})$ released from dental amalgam filling. Am J Physiol 1990; 258(4):939-945.

32. Sukel PP. Signs \& symptoms of mercury vapor exposure from mercury amalgam dental fillings. 2000. [acessado 2005 Jul 15]. Disponível em: http://www. sukel.com/merc-exp.htm 
33. Campos TN, Steagall L. Observação da emissão de vapor de mercúrio com técnica do sulfeto de selênio. Parte II. Correlação entre a proporção do mercúrio e a área do halo. Rev Assoc Paul Cir Dent 1988; 42(5):311-315.

34. Gronka PA, Bobkoskie RL, Tomchick GJ, Bach E, Rakow AB. Mercury vapor exposures in dental offices. J Am Dent Assoc 1970; 81(4):923-925.

35. Ferreira RCH, Appel LE. Recuperação de mercúrio em sobras de amálgama odontológico. 1991. [acessado 2005 Jul 20]. Disponível em: http:// www.unilivre.org.br/banco_de_dados/experiencias/ experiencias/185.htm

36. Elizaur Benitez AB, Dinelli W, Fuller JB. Toxicidade do mercúrio: um perigo constante na odontologia. Odontologia Clínica 1994; 4(1):9-13.

37. Pinto EJ, Iacobucci F, Fichman DM. Contaminação por mercúrio - um levantamento do comportamento do cirurgião-dentista frente ao risco. Revista Paulista de Odontologia 1990; 12(3):39-42.

38. Friberg L, Kullman L, Lind B, Nylander M. Mercury in the central nervous system in relation to amalgam fillings. Swed Med J 1986; 83(7):519-522.

39. Nylander M. Mercury in pituitary glands of dentists. United Kingdom: Lancet; 1986.

40. Nylander M, Friberg L, Lind B. Mercury concentrations in the human brain and kidneys in relation to exposure from dental amalgam fillings. Swed Dent $J$ 1987; 11(5):179-187.

41. Eggleston DW, Nylander M. Correlation of dental amalgam with mercury in brain tissue. J Prosth Dent 1987; 58(6):704-707.

42. Drasch G, Schupp I, Höfl H, Reinke R, Roider G. Mercury Burden of Human Fetal and Infant Tissues. Eur J Pediatrics 1994; 153(8):607-610.

43. Snapp KR, Boyer DB, Peterson LC, Svare CW. The contribution of dental amalgam to mercury in blood. J Dent Res 1989; 68:780-785.

44. Molin M, Bergman B, Marklund SL, Schütz A, Skerfving S. Mercury, selenium, and glutathione peroxidase before and after amalgam removal in man. Acta Odontol Scand 1990; 48(3):189-202.

45. Naleway C, Sakaguchi R, Mitchell E, Muller T, Ayer WA, Hefferren JJ. Urinary mercury levels in US dentists, 1975-1983: review of Health Assessment Program. J Am Dent Assoc 1985; 111(1):37-42.

46. World Health Organization. Inorganic Mercury. Geneva. Environmental Health Criteria 118. 1991. [acessado 2005 Jun 23]. Disponível em: http://www. inchem.org/documents/ehc/ehc/ehc118.htm

47. Lâmpadas do apagão têm risco ambiental. Folha de São Paulo 2001 Jun 06; p. 5.

48. Rupp NW, Paffenbarger GC. Significance to health of mercury used in dental practice: a review. $J$ Am Dent Assoc 1971; 82(14):1401-1407.
49. Fortes CBB, Samuel SMW. Avaliação de meios para armazenagem de resíduos de amálgama de prata. Revista da Faculdade de Odontologia de Porto Alegre 1999; 40(1):36-40.

50. American Dental Association. 2005. [acessado 2005 Jun 23]. Disponível em: http://www.ada.org

51. Fiskesjo G. The effect of two organic mercury compounds on human leukocytes in vitro. Hereditas 1970; 64(1):142-6.

52. Vimy MJ, Lorscheider FL. Intra-oral air mercury released from dental amalgam. J Dent Res 1985; 64(13):1069-1071.

53. Frikholm KO. On mercury from dental amalgam. Its toxic and allergic effects and some comments on occupational hygiene. Acta Odontol Scand 1957; 15:1-108.

54. Jones DW. Exposure or absorption and the crucial question of limits for mercury. J Can Dent Res 1999; 65(1):42-46.

55. Valenzuela NP. Tratamiento de los desechos de amalgama: una forma de disminuir la contaminación ambiental por el mercurio. Odontol Chil 1985; 33(1):17-20.

56. Leite JYP, Souza CP, Araujo AD. Uma rota tecnológica para a recuperação e reciclagem do amálgama oriundo de gabinetes odontológicos. Anais do Congresso Anual da ABM-Associação Brasileira de Metalurgia e Materiais; 1996; São Paulo. p. 225-234.

57. Souza RA, Marchesan MA, Spanó JCE, Silva RS, Pecora JD. Método de remoção de mercúrio dos resíduos de amálgama odontológico. $15^{a}$ Reunião Anual da SBPqO - Sociedade Brasileira de Pesquisa Odontológica; 1998; Águas de São Pedro. p. 11.

58. Koral SM. The scientific case against amalgam. 2002. [acessado 2005 Jun 23]. Disponível em: http:// www.iaomt.com/documents/the $\% 20$ cientific $\% 20$ case $\% 20 \%$ Against $\% 20$ Amalgam.pdf

59. Resolução SS-15 de 18 de janeiro de 1999. Aprova norma técnica que estabelece condições para instalação e funcionamento de estabelecimentos de assistência odontológica, e da providência correlatas. Diário Oficial do Estado de São Paulo 1999; 18 jan.

60. Occupational Safety \& Health Administration. 2003. [acessado 2005 Jul 12]. Disponível em: http://www. osha.gov/SLTC/mercury/index.htlm

Artigo apresentado em 22/08/2005

Aprovado em 18/09/2006

Versão final apresentada em 25/10/2006 